Paulina Krakowska, Edyta Puskarczyk, Magdalena Habrat

AGH Akademia Górniczo-Hutnicza im. St. Staszica w Krakowie

Wydział Geologii, Geofizyki i Ochrony Środowiska

Paweł Madejski

AGH Akademia Górniczo-Hutnicza im. St. Staszica w Krakowie

Wydział Inżynierii Mechanicznej i Robotyki

Mariusz Jędrychowski

AGH Akademia Górniczo-Hutnicza im. St. Staszica w Krakowie

Wydział Fizyki i Informatyki Stosowanej

\title{
Parametry geometryczne przestrzeni porowej niskoporowatych piaskowców kambryjskich wyznaczone na podstawie wyników badań laboratoryjnych na próbkach z rdzeni wiertniczych
}

\begin{abstract}
Parametry geometryczne przestrzeni porowej skał pozwalają oszacować ich zdolności filtracyjne. Wysokorozdzielcza rentgenowska tomografia komputerowa dostarcza wiele różnorodnych parametrów ilościowych przestrzeni porowej. Niektóre $\mathrm{z}$ tych parametrów mogą być skonfrontowane $\mathrm{z}$ wynikami badań laboratoryjnych spektrometrii magnetycznego rezonansu jądrowego (NMR) i porozymetrii rtęciowej (MICP), np. średnia średnica porów. Piknometria helowa, rentgenowska tomografia komputerowa, spektroskopia magnetycznego rezonansu jądrowego i porozymetria rtęciowa dostarczają kluczowej informacji na temat wielkości porowatości. Przepuszczalność absolutna (wyznaczona metodą zaniku ciśnienia, ang. pressure-decay permeability, i impulsu, ang. pulse-decay permeability) pozwala ocenić zdolności filtracyjne skały. Na podstawie obrazów tomograficznych obliczono takie parametry przestrzeni porowej jak: liczba wokseli w obiekcie, pole powierzchni obiektu, średnica kuli o objętości równej objętości obiektu, maksymalna wartość grubości znaleziona w obiekcie, minimalna wartość grubości znaleziona w obiekcie, średnia grubość obiektu, odchylenie standardowe grubości, parametr określający odstępstwo kształtu obiektu od sfery, wydłużenie obiektu, płaskość obiektu, parametr określający podobieństwo kształtu obiektu do kształtu sferycznego za pomocą odpowiedniego stosunku objętości obiektu do powierzchni obiektu, charakterystyka Eulera, najkrótsza długość obiektu mierzona w danym kierunku (Fereta), najdłuższa długość obiektu mierzona w danym kierunku (Fereta), maksymalna średnica Fereta wyznaczona w kierunku prostopadłym do prostej określonej przez najdłuższą średnicę Fereta w obiekcie, stosunek maksymalnej długości średnicy Fereta wyznaczonej w kierunku prostopadłym do prostej określonej przez najkrótszą średnicę Fereta do długości najkrótszej średnicy Fereta, współczynnik kształtu (ShapeVa3D), moment bezwładności wokół najkrótszej osi głównej, moment bezwładności wokół średniej osi głównej, moment bezwładności wokół najdłuższej osi głównej. Dokonano interpretacji liczby porów i mikroszczelin w każdej analizowanej próbce poprzez analizę liczby obiektów w danej klasie objętości. Obrazy tomograficzne były interpretowane jakościowo i ilościowo przy wykorzystaniu programu poROSE (poROus materials examination SoftwarE), który jest wynikiem prac badawczych prowadzonych wspólnie przez ośrodki naukowe i przemysłowe na materiałach porowatych. Analizie poddano wartości porowatości (całkowitej i efektywnej), średnic porów (średnice Fereta, parametr grubości obiektu), parametrów określających kształt porów (np. wydłużenie, sferyczność, spłaszczenie) oraz stosowanych we wzorze Kozeny’ego-Carmana (np. wewnętrzna powierzchnia właściwa porów na jednostkę objętości porów). Przedstawiono wyniki analiz dla próbek zwięzłych piaskowców kambryjskich, będących potencjalnie skałami zbiornikowymi gazu zamkniętego (ang. tight gas). Próbki z rdzeni wiertniczych pochodzą z jednego otworu wiertniczego, z tej samej głębokości poboru rdzenia.
\end{abstract}

Słowa kluczowe: petrofizyka, rentgenowska tomografia komputerowa, przestrzeń porowa, porowatość, przepuszczalność. 


\title{
Geometric parameters of the pore space of low-porosity Cambrian sandstones determined on the basis of laboratory measurements results on core samples
}

\begin{abstract}
Geometric parameters of the rock pore space allow estimating their filtration abilities. High-resolution X-ray computed tomography (CT) provides a great amount of geometric parameters of the pore space. Some of these parameters may be confronted with laboratory measurements of nuclear magnetic resonance spectroscopy (NMR) and mercury porosimetry (MICP), e.g. average pore diameter. Helium pycnometry, CT, NMR and MICP provide key information on the porosity. Absolute permeability allows to assess the filtration abilities of the rock. The following pore space parameters for the object were calculated on the basis of tomographic images: number of voxels, surface area, diameter of the sphere equal to the volume of the object, maximum thickness, minimum thickness, average thickness, standard deviation of thickness, parameter defining the deviation of the shape of the object from the sphere, elongation, flatness, parameter determines the similarity of the shape of the object to the spherical shape using the appropriate ratio of the object's volume to the object's surface, Euler number, the shortest and the longest length measured in a given direction (Feret), maximum Feret diameter determined in the direction perpendicular to the line defined by the longest Feret diameter in the object, ratio of the maximum length of the Feret diameter, attached in a direction perpendicular to the line defined by the shortest Feret diameter up to the shortest Feret diameter, shape coefficient (ShapeVa3D), moment of inertia around the shortest, mean and the longest major axis. The number of pores and microfractures in each of the analyzed samples were interpreted by analyzing the number of objects in a given volume class. The tomographic images were interpreted using the poROSE software (poROus materials examination SoftwarE), which is the result of research carried out jointly by scientific and industrial centers on porous materials. The analysis covered the values of porosity, pore diameters (Feret, thickness), parameters determining pore shape (e.g. elongation, sphericity, flatness) and used in the Kozeny-Carmana formula (e.g. internal pore surface per pore volume). The results of analyzes for tight Cambrian sandstones samples, potentially the tight gas reservoir rocks, are presented. Samples from cores come from one well, with the same probing depth.
\end{abstract}

Key words: petrophysics, computed X-ray tomography, pore space, porosity, permeability.

\section{Wprowadzenie}

Parametry geometryczne przestrzeni porowej stanowią kluczowy element w oszacowaniu zdolności filtracyjnych i potencjału zbiornikowego skał [8]. Znajomość jedynie porowatości całkowitej i efektywnej wraz z przepuszczalnością absolutną w zwięzłych skałach (np. gazu zamkniętego, tzw. tight gas) nie jest wystarczająca. Połączenie informacji $\mathrm{z}$ różnych metod badawczych pozwala w pełni scharakteryzować przestrzeń porową. W pracy przedstawiono wyniki analiz obrazów tomograficznych próbek skalnych na podstawie rentgenowskiej tomografii komputerowej (o podwyższonej rozdzielczości: skala nano, CT) $[1,9,10]$, wsparte wynikami tradycyjnych metod laboratoryjnych: piknometrii helowej (He pycn), porozymetrii rtęciowej (MICP), spektrometrii magnetycznego rezonansu jądrowego (NMR) oraz pomiaru przepuszczalności metodą zaniku ciśnienia (ang. pressure-decay permeability) i impulsu (ang. pulse-decay permeability). Do interpretacji wyników rentgenowskiej tomografii komputerowej wykorzystano program poROSE, który jest wynikiem współpracy badawczej ośrodków naukowych i przemysłowych.

\section{Materiał i metoda}

Materiał badawczy stanowią trzy próbki piaskowców kambryjskich, pobrane z tej samej głębokości, około $3400 \mathrm{~m}$. Otwór wiertniczy zlokalizowany jest w obrębie syneklizy perybałtyckiej. Podstawowe parametry przestrzeni porowej z różnych metod badawczych: rentgenowskiej tomografii komputerowej (CT), piknometrii helowej (He pycn), porozymetrii rtęciowej (MICP), spektrometrii magnetycznego rezonansu jądrowego (NMR) oraz pomiaru przepuszczalności zostały przedstawione w tablicy 1 .

Rentgenowska tomografia komputerowa (CT) to metoda pozwalającą na dwu- $\mathrm{i}$ trójwymiarowe obrazowanie przestrzeni porowej i szkieletu mineralnego skał [2, 4]. Przestrzeń po- rowa i szkielet skalny mogą zostać szczegółowo sparametryzowane, a także oszacowane jakościowo, np. jakość wykształcenia przestrzeni porowej [6].

W badaniach użyto tomografu Nanotom S firmy General Electric z lampą rentgenowską o mocy $57 \mathrm{~W}$ i o maksymalnym napięciu pracy $180 \mathrm{kV}$. Zastosowano detektor firmy Hamamatsu HAM C 7942CA-02, który pozwolił uzyskać rozdzielczość obrazu $800 \mathrm{~nm}$. Obrazy tomograficzne były interpretowane jakościowo i ilościowo przy wykorzystaniu programu poROSE (poROus materials examination SoftwarE) [3, 7]. Program poROSE jest wynikiem prac badawczych prowadzonych wspólnie przez ośrodki naukowe i przemysłowe na materiałach porowatych. 
Autorami programu są: Paulina Krakowska, Edyta Puskarczyk, Magdalena Habrat, Paweł Madejski oraz Mariusz Jędrychowski (AGH w Krakowie). Za pomocą programu możliwe jest przeprowadzenie interpretacji jakościowej i ilościowej obrazów materiałów porowatych, np. wyników CT, FIB-SEM, czy SEM. W pracy skupiono się na możliwościach rentgenowskiej tomografii komputerowej w wyznaczaniu parametrów geometrycznych przestrzeni porowej skał.

Próbka B odznacza się najwyższą wartością porowatości całkowitej z piknometrii helowej i rentgenowskiej tomografii komputerowej, natomiast próbka $\mathrm{C}$ - najniższą. Próbka B wykazuje także najwyższą wartość porowatości efektywnej z po- rozymetrii rtęciowej, a próbka $\mathrm{C}$ - najniższą. Wyniki z porozymetrii rtęciowej mogą być zawyżone w porównaniu do innych metod laboratoryjnych. Prawdopodobnie podczas pomiaru (wysokie ciśnienia wtłaczania) próbki mogły ulec dezintegracji, co znacznie podwyższyło wartość porowatości efektywnej. Różnica w wartościach średnich średnic porów z porozymetrii rtęciowej oraz magnetycznego rezonansu jądrowego może wynikać z zastosowania ogólnych wzorów, zwłaszcza w przypadku określania średniej średnicy porów z NMR. Próbka A charakteryzuje się najwyższymi wartościami porowatości całkowitej i efektywnej ze spektroskopii NMR, średniej średnicy porów z NMR oraz przepuszczalności absolutnej.

Tablica 1. Parametry zbiornikowe (porowatość całkowita i efektywna, przepuszczalność absolutna) i geometryczne (średnice porów)

\begin{tabular}{|c|c|c|c|c|c|c|c|c|}
\hline \multirow{2}{*}{ Próbka } & $\varphi$ He pycn & $\varphi$ eff MICP & $\varphi$ NMR & $\varphi$ eff NMR & $\varphi$ CT & d MICP & d NMR & K \\
\cline { 2 - 10 } & {$[\%]$} & {$[\%]$} & {$[\%]$} & {$[\%]$} & {$[\%]$} & {$[\mu \mathrm{m}]$} & {$[\mu \mathrm{m}]$} & {$[\mathrm{mD}]$} \\
\hline A & 4,70 & 4,45 & 2,00 & 0,89 & 1,70 & 0,1828 & 1,1075 & 0,755 \\
\hline B & 4,92 & 4,63 & 1,24 & 0,58 & 4,10 & 0,1137 & 0,6552 & 0,625 \\
\hline C & 2,06 & 1,80 & 1,04 & 0,33 & 0,05 & 0,1098 & 0,7131 & 0,341 \\
\hline
\end{tabular}

Symbole: $\varphi$ He pycn - porowatość całkowita z piknometrii helowej, $\varphi$ eff MICP - porowatość efektywna z porozymetrii rtęciowej (MICP), $\varphi$ NMR porowatość całkowita ze spektrometrii magnetycznego rezonansu jądrowego (NMR), $\varphi$ eff NMR - porowatość efektywna ze spektrometrii magnetycznego rezonansu jądrowego (NMR), $\varphi \mathrm{CT}$ - porowatość całkowita z rentgenowskiej tomografii komputerowej (CT), d MICP - średnia średnica porów z MICP, d NMR - średnia średnica porów z NMR, K - przepuszczalność absolutna

\section{Wyniki}

Obrazy tomograficzne posłużyły wyznaczeniu parametrów geometrycznych porów (obiektów) i mikroszczelin zidentyfikowanych w próbkach. W tablicy 2 przedstawiono liczbę obiektów w danej klasie objętości. Próbka A odróżnia się znacznie większą liczbą obiektów w stosunku do próbki C. Próbka B odznacza się największą liczbą obiektów o największych

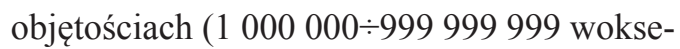
li). W próbce $\mathrm{C}$ nie zidentyfikowano obiektów (porów, mikroszczelin) w wyższych klasach objętości.

Na rysunkach 1-3 przedstawiono wizualizację 3D przestrzeni porowej analizowanych próbek.

Obliczono także następujące wybrane parametry porów i mikroszczelin we wszystkich próbkach:

-Volume - objętość, lliczba wokseli w obiekcie,

- Surface Area - pole powierzchni obiektu wyrażone w wokselach, które bezpośrednio sąsiadują z otoczeniem obiektu,

- Equivalent Diameter - średnica kuli o objętości równej objętości obiektu,

- Thickness Max - maksymalna wartość grubości znaleziona w obiekcie,
Tablica 2. Klasy objętości porów i mikroszczelin w próbkach

\begin{tabular}{|c|c|r|r|r|}
\hline \multirow{2}{*}{ Klasa objętości } & \multirow{2}{*}{ Kolor } & A & B & C \\
\cline { 1 - 3 } woksel & czerwony & 2248 & 1844 & 720 \\
\hline $1-99$ & pomarańczowy & 3965 & 1075 & 545 \\
\hline $100-999$ & żółty & 3802 & 1111 & 174 \\
\hline $1000-9999$ & zielony & 1252 & 994 & 30 \\
\hline $10000-99999$ & jasnoniebieski & 137 & 262 & 2 \\
\hline $100000-999999$ & ciemnoniebieski & 3 & 34 & 0 \\
\hline $1000000-999999999$ & RAZEM & $\mathbf{1 1 4 0 7}$ & $\mathbf{5 3 2 0}$ & $\mathbf{1 4 7 1}$ \\
\hline
\end{tabular}

- Thickness Min - minimalna wartość grubości znaleziona w obiekcie,

- Thickness Mean - średnia grubość obiektu,

- Thickness Std - odchylenie standardowe grubości,

- Anisotropy - parametr określający odstępstwo kształtu obiektu od sfery, liczony na podstawie momentów bezwładności,

- Elongation - wydłużenie obiektu, liczone na podstawie momentów bezwładności,

- Flatness - płaskość obiektu, liczona na podstawie momentów bezwładności, 
- Sphericity - określa podobieństwo kształtu obiektu do kształtu sferycznego za pomocą odpowiedniego stosunku objętości obiektu do powierzchni obiektu,

- Euler Sum - charakterystyka Eulera,

- Feret Min - najkrótsza średnica Fereta, najkrótsza długość obiektu mierzona w danym kierunku,

- Feret Max - najdłuższa średnica Fereta, najdłuższa długość obiektu mierzona w danym kierunku,

- Feret Breadth - maksymalna średnica Fereta wyznaczona w kierunku prostopadłym do prostej określonej przez najdłuższą średnicę Fereta w obiekcie,

- Feret Shape - stosunek maksymalnej długości średnicy Fereta wyznaczonej w kierunku prostopadłym do prostej określonej przez najkrótszą średnicę Fereta do długości najkrótszej średnicy Fereta,

- ShapeVa3D - współczynnik kształtu, liczony na podstawie powierzchni obiektu i pola przekroju kształtu obiektu,

- $\quad$ I1 - moment bezwładności wokół najkrótszej osi głównej,

- $\quad$ I2 - moment bezwładności wokół średniej osi głównej,

- I3 - moment bezwładności wokół najdłuższej osi głównej. W tablicy 3 zestawiono wyniki obliczeń dla największych obiektów zidentyfikowanych w próbkach ze względu na ich możliwe zdolności filtracyjne.

Próbka A charakteryzuje się najlepszymi własnościami zbiornikowymi i parametrami geometrycznymi porów z MICP i NMR - średnią średnicą porów. Natomiast analiza obrazów CT wykazała, że w próbce B zidentyfikowano największy obiekt w przestrzeni porowej i nie jest to mikroszczelina. Największy obiekt w próbkach A i B ma podobną grubość - około 50 pikseli, czyli około $40 \mu \mathrm{m}$, jednakże próbka A wykazuje większą zmienność tego parametru (Thickness Std). Próbka B charakteryzuje się najwyższą wartością średnicy kuli o objętości równej objętości obiektu (Equivalent Diameter), a także powierzchnią właściwą (Surface Area). W próbce B zidentyfikowano największe średnice Fereta (Feret Max). Obiekty w trzech próbkach są mocno wydłużone (Elongation) i odbiegają od kształtu kuli (Sphericity). Parametr ShapeVa3D informuje o wklęsłości lub skręceniu obiektu, stąd w obiekcie w próbce A można się spodziewać bardziej skomplikowanego geometrycznie kształtu.

Wewnętrzna powierzchnia właściwa porów na jednostkę objętości porów (parametr $s_{V p}$ ) jest parametrem wyznaczanym na podstawie analiz ciśnień kapilarnych lub obrazów petrograficznych. CT także umożliwia wyznaczenie tego parametru. Parametr $s_{V p}$ znacznie różni się w wartościach obliczonych na podstawie wzorów Kozeny’ego i CT. Wzór Kozeny’ego-Carmana sprawdza się przy założeniu, które nie zawsze, a raczej rzadko jest spełnione w skałach, tym bardziej o obniżonej porowatości i przepuszczalności. Na podstawie wzoru Kozeny'ego (założenie: przestrzeń porowa zbudowana jest z pakietu

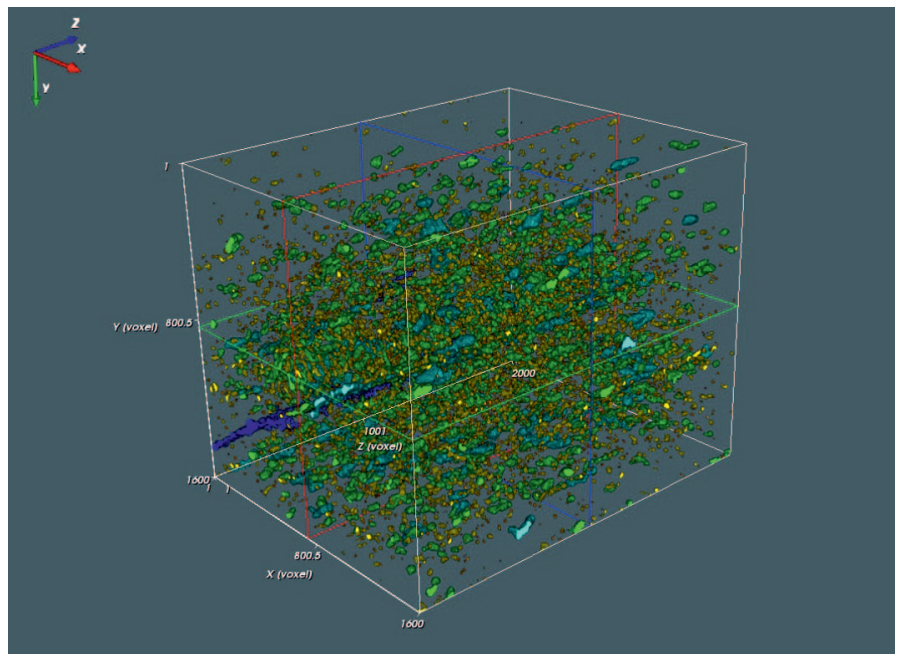

Rys. 1. Trójwymiarowy obraz próbki A na podstawie wyników CT - widoczna mikroszczelina (kolor niebieski). Kolory odpowiadają klasom objętości porów opisanym w tablicy 2 .

Okno programu poROSE

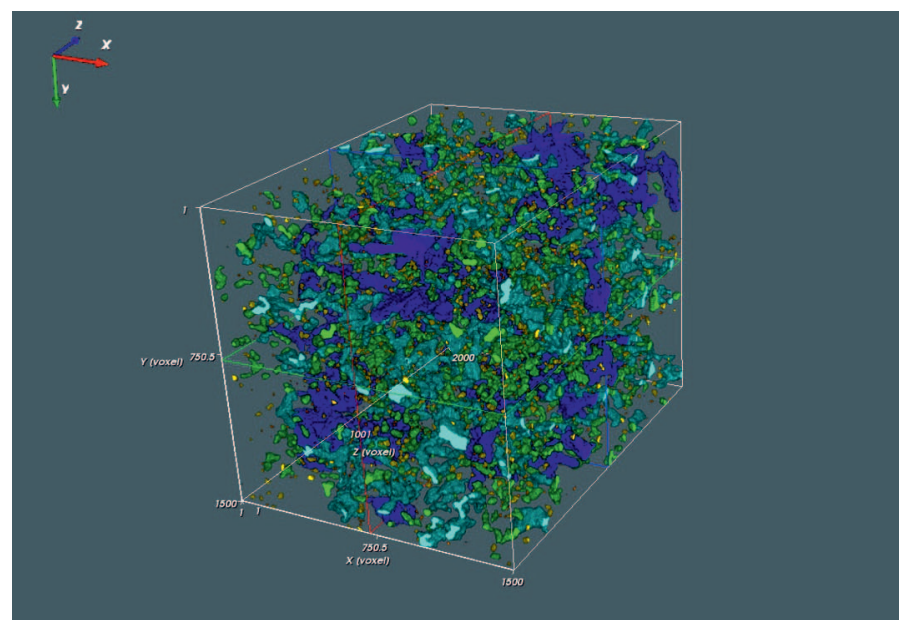

Rys. 2. Trójwymiarowy obraz próbki B na podstawie wyników CT. Kolory odpowiadają klasom objętości porów opisanym w tablicy 2. Okno programu poROSE

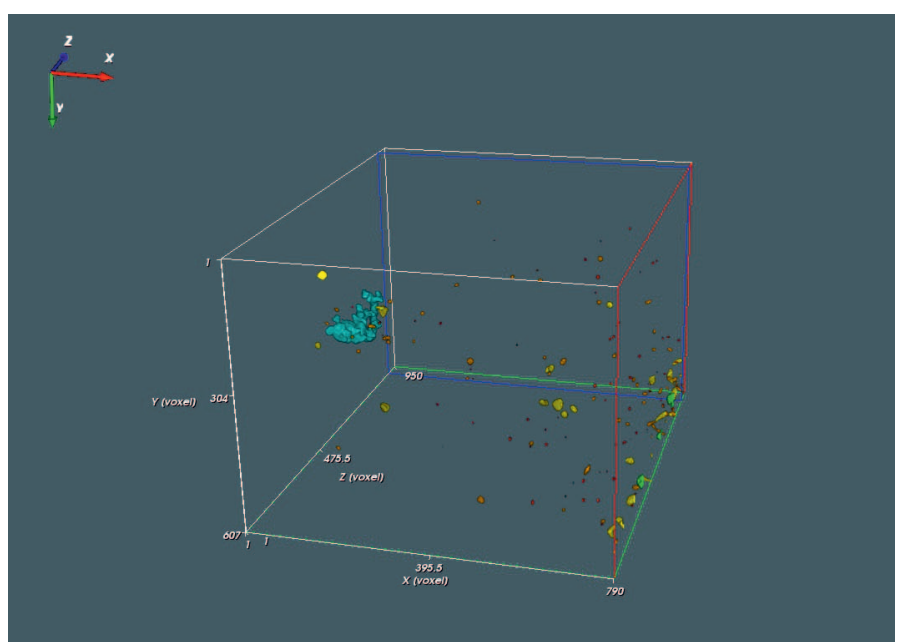

Rys. 3. Trójwymiarowy obraz fragmentu próbki C na podstawie wyników CT. Kolory odpowiadają klasom objętości porów opisanym w tablicy 2 . Okno programu poROSE 
rurek kapilarnych) [5] oraz wyników badań laboratoryjnych (przepuszczalności absolutnej i porowatości efektywnej) wyznaczono wewnętrzną powierzchnię właściwą porów na jednostkę objętości porów $\left(s_{V p}\right)$ oraz powierzchnię właściwą na jednostkę objętości ziaren $\left(s_{V g r}\right)$. Parametry wyniosły odpowiednio: $54614 \mathrm{~cm}^{-1}$, $61274 \mathrm{~cm}^{-1}, 51692 \mathrm{~cm}^{-1}$ dla $s_{V p}$ oraz $2541 \mathrm{~cm}^{-1}$, $2976 \mathrm{~cm}^{-1}, 946 \mathrm{~cm}^{-1}$ dla $s_{V g r}$. Na podstawie wyników badań tomograficznych - pola powierzchni porów i objętości porów obliczono parametr $\mathrm{s}_{\mathrm{Vp}}$, który znacząco odbiega od wartości opisanych wyżej, kolejno wartości: $4,4 \mathrm{~cm}^{-1}$, $4,8 \mathrm{~cm}^{-1}$ i $8,3 \mathrm{~cm}^{-1}$.
Tablica 3. Parametry największego obiektu zidentyfikowanego w danej próbce. Opis parametrów w tekście. 1 woksel (piksel w 3D) ma wymiary: $0,8 \times 0,8 \times 0,8 \mu \mathrm{m}(\mathrm{vx}) .1$ piksel $(\mathrm{px})=0,8 \mu \mathrm{m}$

\begin{tabular}{|l|c|c|c|}
\hline \multicolumn{1}{|c|}{ Parametr } & A & B & C \\
\hline Volume [vx] & 240512 & 2680076 & 182819 \\
\hline Surface Area $\left[\mathrm{px}^{2}\right.$ ] & 41406 & 422888 & 55839 \\
\hline Equivalent Diameter [px] & 77 & 172 & 70 \\
\hline Thickness Max [px] & 49 & 50 & 26 \\
\hline Thickness Min [px] & 2 & 2 & 2 \\
\hline Thickness Mean [px] & 35 & 32 & 16 \\
\hline Thickness Std [px] & 13 & 9 & 5 \\
\hline Anisotropy & 0,57 & 0,85 & 0,86 \\
\hline Elongation & 0,86 & 0,94 & 0,90 \\
\hline Flatness & 0,51 & 0,16 & 0,16 \\
\hline Sphericity & 0,43 & 0,15 & 0,14 \\
\hline Euler Sum & 1 & -4 & -1 \\
\hline Feret Min [px] & 82 & 238 & 77 \\
\hline Feret Max [px] & 154 & 655 & 239 \\
\hline Feret Breadth [px] & 102 & 387 & 122 \\
\hline Feret Shape & 1,87 & 2,76 & 3,10 \\
\hline ShapeVa3D & 0,45 & 0,22 & 0,28 \\
\hline I1 & 292644245 & $1,03742 \mathrm{E}+11$ & 887269266 \\
\hline I2 & 250807923 & 97144301437 & 802051353 \\
\hline I3 & 127014119 & 15464482536 & 127819676 \\
\hline
\end{tabular}

\section{Wnioski}

Na podstawie wyników CT sparametryzowano obiekty przestrzeni porowej i przedstawiono wyniki dla obiektów o największej objętości, które będą odgrywały znaczącą rolę w prawdopodobnym przepływie mediów złożowych. Rentgenowska tomografia komputerowa wspiera standardowe badania laboratoryjne na próbkach z rdzeni wiertniczych w ocenie parametrów geometrycznych przestrzeni porowej, a wręcz pozwala wyznaczyć parametry niemierzalne przez inne metody (np. sferyczność porów, wydłużenia itp.).

Próbka A charakteryzowała się najlepszymi własnościami zbiornikowymi (porowatości z NMR i przepuszczalność ab- solutna), jednakże to w próbce B zaobserwowano najlepsze parametry geometryczne przestrzeni porowej.

Próbki zostały pobrane z rdzenia z tej samej głębokości, zlokalizowane obok siebie. Rozbieżność w wynikach badań laboratoryjnych dla analizowanych trzech próbek piaskowca kambryjskiego jest znacząca. Zaobserwowano silną heterogeniczność wykształcenia przestrzeni porowej piaskowców kambryjskich.

Analiza obrazów tomograficznych wraz z informacją z badań piknometrii helowej, porozymetrii rtęciowej i spektrometrii NMR pozwoliła efektywnie ocenić parametry geometryczne przestrzeni porowej, tym samym ocenić zdolności filtracyjne skał.

\section{Podziękowania}

Autorzy dziękują firmie PGNiG SA za udostępnienie danych geologicznych, petrofizycznych i geofizyki otworowej. Badania laboratoryjne rentgenowskiej tomografii komputerowej wykonano na Wydziale Fizyki i Informatyki Stosowanej AGH w Krakowie. Pozostałe badania laboratoryjne zostały przeprowadzone w Laboratorium Petrofizyki Katedry Geofizyki WGGiOŚ AGH w Krakowie i Instytucie Nafty i Gazu - Państwowym Instytucie Badawczym w Krakowie. Część prac można było wykonać dzięki pracom statutowym Katedry Geofizyki Wydziału Geologii, Geofizyki i Ochrony Środowiska AGH w Krakowie. 
Artykuł powstał na podstawie pracy wykonanej w ramach programu Lider VI, projekt pn.: Nowatorska metodyka interpretacji niekonwencjonalnych złóż ropy i gazu z wykorzystaniem wyników rentgenowskiej tomografii komputerowej - finansowanej przez Narodowe Centrum Badań i Rozwoju; numer umowy LIDER/319/L-6/14/NCBR/2015.

\section{Literatura}

[1] Bielecki J., Jarzyna J., Bożek S., Lekki J., Stachura Z., Kwiatek W.M.: Computed microtomography and numerical study of porous rock samples. Radiation Physics and Chemistry 2013, vol. 93, s. 59-66.

[2] Dohnalik M., Jarzyna J.: Determination of reservoir properties through the use of computed X-ray microtomography - eolian sandstone examples. Geology, Geophysics \& Environment 2015, vol. 41, nr 3, s. 223-248.

[3] Habrat M., Krakowska P., Puskarczyk E., Jędrychowski M., Madejski P.: The concept of a computer system for interpretation of tight rocks using $X$-ray computed tomography results. Studia Geotechnica et Mechanica 2017, vol. 39, nr 1, s. 101-107.

[4] Jarzyna J., Krakowska P., Puskarczyk E., Wawrzyniak-Guz K., Bielecki J., Tkocz K., Tarasiuk J., Wroński S., Dohnalik M.: $X$-ray computed microtomography - A useful tool for petrophysical properties determination. Computational Geoscience 2016, vol. 20, nr 5, s. 1155-1167.

[5] Kozeny J.: Über kapillare Leitung des Wassers im Boden. Sitzungsber Akad. Wiss., Wien 1927, 136(2a), s. 271-306.

[6] Krakowska P., Dohnalik M., Jarzyna J., Wawrzyniak-Guz K.: Computed X-ray microtomography as the useful tool in petrophysics: A case study of tight carbonates Modryn formation from Poland. Journal of Natural Gas Science and Engineering 2016, vol. 31, s. 67-75.

[7] Krakowska P., Puskarczyk E., Jędrychowski M., Habrat M.,

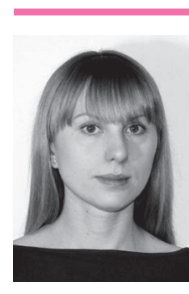

Dr inż. Edyta PUSKARCZYK

Adiunkt na Wydziale Geologii, Geofizyki i Ochrony

Środowiska

Akademia Górniczo-Hutnicza im. St. Staszica

al. Mickiewicza 30

30-059 Kraków

E-mail:puskar@agh.edu.pl

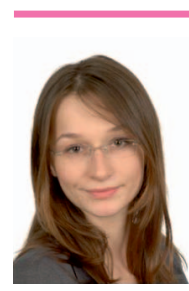

Mgr inż. Magdalena HABRAT

Asystent na Wydziale Geologii, Geofizyki i Ochrony

Środowiska

Akademia Górniczo-Hutnicza im. St. Staszica

al. Mickiewicza 30

30-059 Kraków

E-mail:mladniak@agh.edu.pl
Madejski P., Dohnalik M.: Innovative characterization of tight sandstones from Paleozoic basins in Poland using X-ray computed tomography supported by nuclear magnetic resonance and mercury porosimetry. Journal of Petroleum Science and Engineering 2018, vol. 166, s. 389-405.

[8] Leśniak G.: Zastosowanie komputerowej analizy obrazu w badaniach petrofizycznych. Przegląd Geologiczny 1999, vol. 47, nr 7, s. 644-651.

[9] Zalewska J. (red.): Rentgenowska mikrotomografia komputerowa $w$ badaniu skat weglanowych. Prace Naukowe Instytutu Nafty i Gazu 2010, nr 71, s. 1-264.

[10] Zalewska J., Dohnalik M., Kaczmarczyk J., Poszytek A., Sikora G., Cebulski D., Masłowski M., Biały E.: Rentgenowska mikrotomografia komputerowa w badaniu skat węglanowych. Prace Naukowe Instytutu Nafty i Gazu 2010, nr 171, s. 1-264.

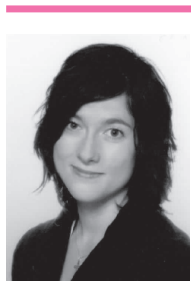

Dr inż. Paulina KRAKOWSKA

Adiunkt na Wydziale Geologii, Geofizyki

i Ochrony Środowiska

Akademia Górniczo-Hutnicza im. St. Staszica

w Krakowie

al. Mickiewicza 30, 30-059 Kraków

E-mail.krakow@agh.edu.pl

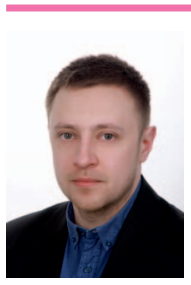

Dr inż. Paweł MADEJSKI

Adiunkt na Wydziale Inżynierii Mechanicznej i Robotyki

Akademia Górniczo-Hutnicza im. St. Staszica

al. Mickiewicza 30

30-059 Kraków

E-mail: madejski@agh.edu.pl

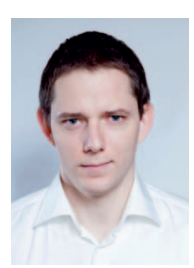

Dr inż. Mariusz JĘDRYCHOWSKI

Asystent na Wydziale Fizyki i Informatyki Stosowanej Akademia Górniczo-Hutnicza im. St. Staszica al. Mickiewicza 30

30-059 Kraków

E-mail: mariusz.jedrychowski@fis.agh.edu.pl 